\title{
Parathyroid hormone/parathyroid hormone-related peptide regulate osteosarcoma cell functions: Focus on the extracellular matrix (Review)
}

\author{
DRAGANA NIKITOVIC ${ }^{1}$, RAFAELA-MARIA KAVASI ${ }^{1}$, AIKATERINI BERDIAKI $^{1}$, \\ DIONYSIOS J. PAPACHRISTOU ${ }^{2}$, JOHN TSIAOUSSIS ${ }^{1}$, DEMETRIOS A. SPANDIDOS ${ }^{3}$, \\ ARISTIDES M. TSATSAKIS ${ }^{4}$ and GEORGE N. TZANAKAKIS ${ }^{1}$ \\ ${ }^{1}$ Department of Anatomy-Histology-Embryology, School of Medicine, University of Crete, \\ Heraklion 71003; ${ }^{2}$ Department of Anatomy-Histology-Embryology, Unit of Bone and Soft Tissue Studies, \\ School of Medicine, University of Patras, Patras 26504; ${ }^{3}$ Laboratory of Clinical Virology, and \\ ${ }^{4}$ Laboratory of Toxicology, Medical School, University of Crete, Heraklion 71003, Greece
}

Received May 18, 2016; Accepted July 15, 2016

DOI: 10.3892/or.2016.4986

\begin{abstract}
Osteosarcoma (OS) is a primary bone tumor of mesenchymal origin mostly affecting children and adolescents. The OS extracellular matrix (ECM) is extensively altered as compared to physiological bone tissue. Indeed, the main characteristic of the most common osteoblastic subtype of OS is non-mineralized osteoid production. Parathyroid hormone (PTH) is a polypeptide hormone secreted by the chief cells of the parathyroid glands. The PTH-related peptide (PTHrP) may be comprised of 139, 141 or 173 amino acids and exhibits considerate $\mathrm{N}$-terminal amino acid sequence homology with PTH. The function of PTH/PTHrP is executed through the activation of the PTH receptor 1 (PTHR1) and respective downstream intracellular pathways which regulate skeletal development, bone turnover and mineral ion homeostasis. Both PTHR1 and its PTH/PTHrP ligands have been
\end{abstract}

Correspondence to: Dr Dragana Nikitovic, Department of Anatomy-Histology-Embryology, School of Medicine, University of Crete, Heraklion 71003, Greece

E-mail: dnikitovic@med.uoc.gr

Abbreviations: OS, osteosarcoma; ECM, extracellular matrix; MSCs, mesenchymal stem cells; PTH, parathyroid hormone; PTHR1, parathyroid hormone receptor 1; GPCR, G-protein-coupled receptor; PTHrP, parathyroid hormone-related peptide; CREB, cAMP response element-binding protein; PGs, proteoglycans; GAGs, glycosaminoglycans; FGF, fibroblast growth factor; Runx-2, runt-related transcription factor 2; SLRPs, small leucine-rich repeat proteoglycans; HA, hyaluronan; MMPs, matrix metalloproteinases

Key words: parathyroid hormone, parathyroid hormone-related peptide, parathyroid hormone receptor 1, osteosarcoma, extracellular matrix, signaling, hyaluronan, proteoglycans shown to be expressed in OS and to affect the functions of these tumor cells. This review aims to highlight the less well known aspects of PTH/PTHrP functions in the progression of OS by focusing on ECM-dependent signaling.

\section{Contents}

1. Introduction

2. Parathyroid hormone (PTH) and parathyroid hormonerelated peptide (PTHrP)

3. Parathyroid hormone/parathyroid hormone-related protein receptor (PTH/PTHrP type 1 receptor)

4. PTH/PTHR1 signaling in OS

5. PTH/PTHrP-induced ECM remodeling in OS: Novel insights

6. Conclusions

\section{Introduction}

Osteosarcoma (OS) is the most common primary bone tumor. It affects both children and adolescents (with a second peak incidence in the middle aged population (1). Of note, a higher frequency in males as compared to females has been reported (2). The most common presenting site for OS is the metaphysis of long bone (3) The lesion is defined as a mass composed of transformed osteoblasts secreting various mineralized components of the extracellular matrix (ECM) and is associated with local bone and soft tissue destruction. Conventional OS exhibits 7 distinct pathological subtypes (4). The most commonly diagnosed subtype of OS (approximately $60 \%$ of cases) is the osteoblastic subtype with osteoid matrix as its dominant feature (5). The outcomes for patients do not vary significantly among the subtypes, with the cohort size being a limiting factor, as the numbers of patients with the more rare subtypes are not many in number, and thus patients with different subtypes cannot be effectively compared (6). In the past, the 
disease prognosis was extremely dismal with the mortality rate being $>90 \%$, mostly due to pulmonary metastases (3). During the past decades, more effective treatment regimes have been developed, with the tumor recurrence, however, remaining as high as $30-40 \%$ for all patients (7). Importantly, for the subgroup of patients with established metastatic disease, there is no therapeutic strategy able to establish long-term tumor control (5). The genetic drivers of OS initiation and progression are not conclusively defined. Thus, mutations at the both level of mesenchymal stem cells (MSCs), as well as in committed osteoprogenitors have been implicated in the development of OS (8). Some data obtained from murine models support the hypothesis that the committed osteoblast pool gives rise to the precursor OS cell (9). Furthermore, it has been suggested that the stage of differentiation of the transformed osteoprogenitor predetermines the OS subtype (10). However, as OS is a relatively rare tumor, it is impossible to correlate these subtypes with specific mutations due to the extensive heterogeneity of OS (11) and to the fact that the variety of its subtypes occur in different frequencies (8). On the other hand, it has been suggested that OS originates from MSCs as a consequence of aneuploidization and the genomic loss of Cdkn2 (12). That said, taking into account all of the above, the weight of evidence seems to favor an osteoblastic population as the cell of origin (8).

\section{Parathyroid hormone (PTH) and parathyroid hormone- related peptide (PTHrP)}

PTH is an 84-amino-acid polypeptide hormone (PTH 1-84) which is, along with its fragments (e.g., PTH 1-34 and PTH 7-84), secreted by the chief cells of the parathyroid glands. The function of PTH is perpetrated through the activation of PTH receptor 1 (PTHR1) and respective downstream intracellular pathways $(13,14)$. PTHR1 is a G-protein-coupled receptor (GPCR) that regulates skeletal development, bone turnover and mineral ion homeostasis (15). The PTHR1 receptor can also be activated through PTH-related protein (PTHrP) binding to induce target cells to promote diverse biochemical responses. The most important function of PTH is to increase blood calcium and decrease blood phosphate levels, with principal target organs being the skeleton and the kidneys (13). The feedback between the parathyroid glands and the blood calcium levels regulates the secretion of PTH in an inverse manner (13), and specifically modulates the relative abundance of various PTH-derived peptides that are released into the circulation (16).

The effects of PTH are focused on the osteoid, the highly specialized bone ECM. Of note, PTH inhibits the bone growth-promoting activity of osteoblasts and induces osteoclasts to resorb bone and release calcium and phosphate ions into the blood. Simultaneously, the mobilized phosphate ions are excreted by the kidneys in a PTH-regulated manner (13).

In humans, PTHrP may be comprised of 139, 141 or 173 amino acids, which is dependent on alternative mRNA splicing (17). Importantly, this peptide exhibits considerate $\mathrm{N}$-terminal amino acid sequence homology with PTH and functions likewise through the activation of PTHR1. PTHrP exhibits both paracrine and autocrine function, and has an important role in the regulation of differentiation in the growth plates of developing long bones (18).

\section{Parathyroid hormone/parathyroid hormone-related protein receptor (PTH/PTHrP type 1 receptor)}

PTHR1 is highly expressed in the skeleton and the kidneys $(15,18,19)$. Agonist binding to PTHR1 is coupled with the activation of phospholipase $\mathrm{C}$, adenylyl cyclase, or cyclic adenosine monophosphate (cAMP)/protein kinase A (20-22). Alternatively, Rey et al (23) demonstrated that 'PTH can stimulate p38 in early differentiating osteoblastic cells, probably by a cAMP-PKA-dependent mechanism and that activation of $\mathrm{p} 38$ by PTH is important for the stimulation of ALP and matrix calcification induced by this peptide hormone'.

Moreover, it has been determined that upon PTH binding to PTHR1, the resulting ligand-receptor complex is internalized through the involvement of clathrin-coated pits via an arrestin-dependent mechanism $(24,25)$. Furthermore, it has been suggested that the regulation of GPCR endocytosis is a complex multistep process that involves the catalytic action of several lipid-modifying enzymes (26). Intriguing results came to light upon utilizing structurally modified ligands to analyze PTHR1 downstream signaling. Thus, PTHR1 was found to continue to signal through a G-protein-mediated pathway within endosomes, challenging the established ground rule in GPCR biology of transient membrane receptor activation with subsequent rapid deactivation and receptor internalization (19).

Early toxicological studies using rat models suggested that long-term PTH treatment may increase the risk of developing OS (27). Experiments on both Fisher 344 and Sprague-Dawley rats indicated that the occurence of OS depends on the level of the PTH 1-34 dose and the duration of treatment (27-29). Importantly however, the doses tested in the rat models were a 100-fold higher as compared to the human dose approved by the Food and Drug Administration (30). Up-to-date clinical trials and patient follow-up have not not shown a correlation between PTH 1-34 use and the incidence of OS (31-33). Moreover, in the US post-marketing surveillance study of adult OS and teriparatide treatment, it was determined that after 7 years, there were no patients with OS who had a prior history of teriparatide treatment (33).

\section{PTH/PTHR1 signaling in OS}

PTHR1 was found to be expressed in various tumor tissues, including OS. Importantly, the expression of PTHR1 affects OS cell functions, as it has been reported that the knockdown of PTHR1 decreases invasion and growth, and increases tumor differentiation in vivo (34). In the same study, upon overexpressing PHTR1, an increase in proliferation, motility and in the invasion ability of OS cells was evident. Indeed, this was perpetrated without the addition of exogenous PTHr, thus indicating the existence of autocrine signaling (34). Moreover, the overexpression of PTHR1 in OS leads to increased proliferation and motility, delayed osteoblastic differentiation, as well as in the upregulation of genes that are involved in the production of ECM (34). The function of PTHR1 is regulated at several levels in bone tissue (35). Furthermore, in OS cells, it was demonstrated that the $\mathrm{Na} / \mathrm{H}$ exchanger regulatory factor-1 (NHERF1), which is a cytoplasmic PDZ protein, binds PTHR1 through its PDZ motif to anchor it to the actin skeleton, and thus mediates the downstream signaling of this receptor (36). A feedback 
mechanism is suggested for PTH/PTHR1, as PTH was shown to transcriptionally downregulate $\mathrm{PTH} / \mathrm{PTHrP}$ receptor gene expression in osteoblast-like cells via a cAMP-dependent, PKA-independent pathway (37).

In an early study on OS cells, it was demonstrated that PTH induces c-fos transcription, which is important to bone metabolism. Indeed, the induction of c-fos transcription by PTH appears to occur principally through the activation of PKA, that then targets CREB and the c-fos calcium/cAMP response element (38). Thus, in PTH-treated SaOS2 OS cells, CREB was shown to be phosphorylated at Ser133, leading to the decreased motility of the CREB:CRE complex. The phosphorylated CREB:CRE complex recruits an adaptor protein that enhances c-fos transcription (39).

PTHrP is widely expressed in fetal and adult tissues, and is able to regulate cellular calcium transport, as well as cell proliferation, development and differentiation. The dysregulated expression of PTHrP has shown to correlate with cancer-related pathologies, as the key inducer of malignancy-associated hypercalcemia; however, new developments suggest its crucial participation in the progression of skeletal metastasis (40). In a previous study, it was demonstrated that increased autocrine secretion of, and responsiveness to, PTHrP results in the inhibition of the growth kinetics of the rat osteoblastic OS cell line, UMR 106-01, both in vitro and in vivo (41). Moreover, the osteostatin domain of C-terminal PTHrP induces the activation of Src, extracellular signal-regulated kinase (ERK) and Akt, resulting in the phosphorylation of vascular endothelial growth factor receptor 2 (VEGFR2) in rat osteoblastic OS UMR-106 cells thus, regulating the functions of these cells (42). Two human osteoblast-like OS cell lines show distinct expression and differential regulation of PTHrP expression (43). Furthermore, PTHrP expression possibly mediates the function of bone microenvironment-related growth factors in MG-63 OS cells. It is of clinical relevance that PTHrP and anticancer drugs show opposing interactions on death receptor-triggered, as well as on mitochondrial apoptotic pathways. Thus, stimulation experiments of the CD95-, the TNF-R- and the TRAIL-R-death receptor systems in Saos2 human OS cells revealed that PTHrP can block signaling via each of these death receptors. In addition, PTHrP induces chemoresistance by interference with 53 family-dependent apoptotic signaling pathways, and the p53-mediated transactivation of apoptosis target genes (44).

\section{PTH/PTHrP-induced ECM remodeling in OS: Novel insights}

The ECM is a network of molecules secreted by cells, with an inherent self-assembly ability, that provides structure and organization to tissues. This extensive network is mainly composed of collagens, elastin, proteoglycans (PGs), glycosaminoglycans (GAGs), fibronectins and laminins $(45,46)$. Similar to the cell membrane, the ECM forms an active interface, which is the basis of both out-in and in-out signaling. The constant interactions between cells and ECM components are mostly perpetrated through cell membrane receptors $(47,48)$, whereupon the binding of a ligand results in the activation of a cascade of signaling pathways which in turn induce several cellular responses (49), including proliferation, adhesion, invasion, cell motility and metastasis $(50,51)$.

The OS ECM is extensively altered as compared to physiological bone tissue. Indeed, the main characteristic of the most common osteoblastic subtype of OS is the non-mineralized osteoid production $(52,53)$. Normally, osteoblasts produce a highly specialized ECM, osteoid, which is a complex of mineralized proteins. The changes in the ECM of OS have been directly correlated to disease progression (54-57). Importantly, ECM is a pool of growth factors, hormones, cytokines and other active mediators, whose bioavailability (45) is altered in OS, and may contribute to disease progression (56). Extensive feedback exists among these mediators and the OS ECM content and organization which ultimately regulate OS biological function (54-57). Importantly, a significant facet of PTH function is the regulation of bone ECM, osteoid (58).

Recently, the anabolic effect of PTH 1-34 on bone metabolism has been shown to correlate with changes in fibroblast growth factor-2 (FGF-2) expression. These FGF fluctuations have been shown to modify the nuclear accumulation and subsequent action of runt-related transcription factor 2 (Runx-2) and CREB transcription factors, key in the regulation of osteoblast growth and differentiation (59). Indeed, in a FGF-2-dependent manner, Runx 2 modifies the transcription of genes related to signaling mechanisms perpetrated by PGs, including syndecans, glypicans and versican. Moreover, it has been proposed that Runx2/FGF-2/PG downstream signaling constitutes an ECM-mediated feedback loop that regulates the growth of osteoblastic lineage cells (60). The existence of this signaling axis was recently confirmed in OS cells (61). Thus, PTH 1-34 intermittent treatment induces a significant increase in FGF-2 transcripts. Enhanced FGF-2 signaling decreases the expression of the small leucine-rich repeat proteoglycan (SLRP), biglycan, in a manner positively correlated to MG63 OS cell migration (61). Indeed, Datsis et al speculated that 'the PTH 1-34-FGF-2 axis, by causing strong downregulation of biglycan expression, dramatically changes the ratio among the SLRP members, resulting in altered bioavailability of growth factors involved in OS cell migration' (61). Importantly, the family of SLRPs has shown to be associated with the progression of OS $(51,56,57)$. In particular, decorin seems to affect differentiation of OS cells (62), whereas biglycan, is related to the growth, proliferation and migration of OS cells $(3,57)$. The expression of another SLRP, lumican, was found to be 'positively correlated with the differentiation and negatively with the growth of human OS cells' (51). The GAG chains bound in to PG cores participate in the fine modulation of osteoblastic cell functions (63).

It has been shown that under estrogen deficiency, resulting from bilateral ovariectomy (OVX), ECM proteins, including biglycan, tenascin and fibronectin have an altered expression and distribution in OVX as compared to control animals (64). The increase in biglycan expression has been shown to correlate with the regulation of bone formation and matrix mineralization by facilitating osteoblast differentiation through Erk activation and increased Runx2 transcriptional activity (65). Periostin, a conserved ECM protein, is crucial for the process of tumorigenesis (66). Notably, the expression of this bone matrix protein is regulated by PTH (67). Importantly, periostin 


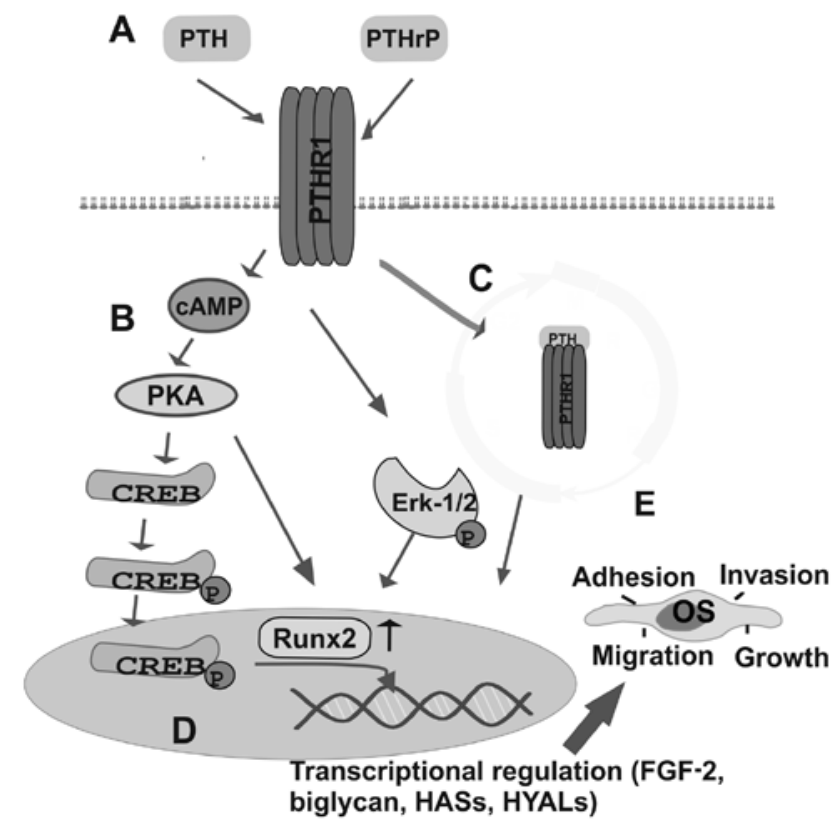

Figure 1. The effect of parathyroid hormone (PTH)/PTH-related peptide (PTHrP)-dependent extracellular matrix (ECM) signaling on osteosarcoma (OS) cell functions. Schematically depicted are: (A) PTH receptor 1 (PTHR1) activation; (B) receptor respective downstream signaling; (C) transcriptional regulation; (D) modulation of ECM-correlated target genes; (E) regulation of basic OS cell functions. CREB, cAMP response element-binding protein; cAMP, cyclic adenosine monophosphate; Runx-2, runt-related transcription factor 2; FGF-2, fibroblast growth factor-2.

was found to be overexpressed in various types of human cancer, where it interacts with multiple cell-surface receptors, most notably integrins, and signals mainly via the PI3-K/Akt to promote cancer cell survival, and metastasis (66).

Another ECM component, the glycosaminoglycan, hyaluronan (HA), was established to regulate cancer cell function $(50,68)$. In an early study, PTH was demonstrated to strongly increase HA synthesis in UMR 106-01 BSP OS cells (69). Moreover, periosteal and endosteal osteoblastic cell populations exhibited metabolic differences in their HA synthesis responses to PTH (70). Interestingly, Berdiaki et al (71) suggest that there is a regulatory effect of PTH 1-34, in an administration mode-dependent manner, on HA metabolism that is essential for OS cell migration. The effects of PTH were shown to correlate with OS cell differentiation and behavior. Specifically, intermittent PTH 1-34 treatment of poorly differentiated and aggressive MG-63 cells increased their HA-synthase-2 expression, which resulted in enhanced high-molecular size HA deposition in the pericellular matrix, in association with the increased ability of these cells to migrate. Interestingly, continuous PTH 1-34 treatment stimulated well-differentiated Saos 2 cell HA production and modestly enhanced their migration (71). Recently, PTH intermittent treatment was shown to increase HA deposition in rat long bones (72).

OS pathogenesis is, additionally, characterized by the differential expression of matrix metalloproteinases (MMPs) which results in ECM integrity disruption (73). MMPs are proteolytic enzymes responsible for ECM remodeling under both pathological and physiological conditions (73-78). Importantly, the overexpression of MMPs has been observed in many types of cancer (77), indicating that their expression may be utilized as a possible prognostic marker (78). Furthermore, it has been suggested, that the increased expression of MMP-1 and -9 may, in OS, predict an adverse outcome such as invasion or metastasis (79-81). Indeed, Husmann et al (76) based on in vivo and in vitro experiments, suggested that MMP-1 overexpression in OS plays an important role in tumor burden and pulmonary metastasis. In a recent study, PTH was shown to increase MMP-13 expression in UMR 106-01 OS cells, as well as in normal osteoblasts (82). On the other hand, the daily injection of rhPTH 1-34 has been shown to result in a decrease in serum Runx2 and MMP-13 levels in post-menopausal women (83). The PTH/PTHrP-dependent ECM signaling on OS cell functions is shown in Fig. 1.

\section{Conclusions}

In conclusion, this review has highlighted the evolving roles that $\mathrm{PTH} / \mathrm{PTR}$ P signaling play in the progression of OS. $\mathrm{PTH} / \mathrm{PTRrP}$ are established to specifically regulate bone remodeling, as well as to participate in the progression of commonly debilitating and degenerative bone diseases. Further progress in discerning the specific signaling pathways of PTH/PTRrP in the pathogenesis of OS is warranted.

\section{References}

1. Mirabello L, Troisi RJ and Savage SA: International osteosarcoma incidence patterns in children and adolescents, middle ages and elderly persons. Int J Cancer 125: 229-234, 2009.

2. Stiller CA, Bielack SS, Jundt G and Steliarova-Foucher E: Bone tumours in European children and adolescents, 1978-1997. Report from the Automated Childhood Cancer Information System project. Eur J Cancer 42: 2124-2135, 2006.

3. Fletcher CDM, Unni KK and Mertens F (eds): World Health Organization Classification of Tumours. Pathology and Genetics of Tumours of Soft Tissue and Bone. IARC Press, Lyon, 2002.

4. Ragland BD, Bell WC, Lopez RR and Siegal GP: Cytogenetics and molecular biology of osteosarcoma. Lab Invest 82: 365-373, 2002.

5. Bacci G, Longhi A, Fagioli F, Briccoli A, Versari M and Picci P: Adjuvant and neoadjuvant chemotherapy for osteosarcoma of the extremities: 27 year experience at Rizzoli Institute, Italy. Eur J Cancer 41: 2836-2845, 2005.

6. Weiss A, Khoury JD, Hoffer FA, Wu J, Billups CA, Heck RK, Quintana J, Poe D, Rao BN and Daw NC: Telangiectatic osteosarcoma: The St. Jude Children's Research Hospital's experience. Cancer 109: 1627-1637, 2007.

7. Jaffe N, Carrasco H, Raymond K, Ayala A and Eftekhari F: Can cure in patients with osteosarcoma be achieved exclusively with chemotherapy and abrogation of surgery? Cancer 95: 2202-2210, 2002.

8. Mutsaers AJ and Walkley CR: Cells of origin in osteosarcoma: Mesenchymal stem cells or osteoblast committed cells? Bone 62: 56-63, 2014.

9. Lin PP, Pandey MK, Jin F, Raymond AK, Akiyama $\mathrm{H}$ and Lozano G: Targeted mutation of p53 and Rb in mesenchymal cells of the limb bud produces sarcomas in mice. Carcinogenesis 30: 1789-1795, 2009.

10. Mutsaers AJ, Ng AJ, Baker EK, Russell MR, Chalk AM, Wall M, Liddicoat BJ, Ho PW, Slavin JL, Goradia A, et al: Modeling distinct osteosarcoma subtypes in vivo using Cre:lox and lineage-restricted transgenic shRNA. Bone 55: 166-178, 2013.

11. Overholtzer M, Rao PH, Favis R, Lu XY, Elowitz MB, Barany F, Ladanyi M, Gorlick R and Levine AJ: The presence of p53 mutations in human osteosarcomas correlates with high levels of genomic instability. Proc Natl Acad Sci USA 100: 11547-11552, 2003.

12. Mohseny AB, Szuhai K, Romeo S, Buddingh EP, Briaire-de Bruijn I, de Jong D, van Pel M, Cleton-Jansen AM and Hogendoorn PC: Osteosarcoma originates from mesenchymal stem cells in consequence of aneuploidization and genomic loss of Cdkn2. J Pathol 219: 294-305, 2009. 
13. Vilardaga JP, Romero G, Friedman PA and Gardella TJ: Molecular basis of parathyroid hormone receptor signaling and trafficking: A family B GPCR paradigm. Cell Mol Life Sci 68: $1-13,2011$.

14. Huan J, Olgaard K, Nielsen LB and Lewin E: Parathyroid hormone 7-84 induces hypocalcemia and inhibits the parathyroid hormone 1-84 secretory response to hypocalcemia in rats with intact parathyroid glands. J Am Soc Nephrol 17: 1923-1930, 2006.

15. Cheloha RW, Gellman SH, Vilardaga JP and Gardella TJ: PTH receptor-1 signalling-mechanistic insights and therapeutic prospects. Nat Rev Endocrinol 11: 712-724, 2015.

16. Friedman PA and Goodman WG: PTH(1-84)/PTH(7-84): A balance of power. Am J Physiol Renal Physiol 290: F975-F984, 2006.

17. Burton DW, Brandt DW and Deftos LJ: Parathyroid hormone-related protein in the cardiovascular system. Endocrinology 135: 253-261, 1994.

18. Kronenberg HM: Developmental regulation of the growth plate. Nature 423: 332-336, 2003

19. Abou-Samra AB, Jüppner H, Force T, Freeman MW, Kong XF Schipani E, Urena P, Richards J, Bonventre JV and Potts JT Jr: Expression cloning of a common receptor for parathyroid hormone and parathyroid hormone-related peptide from rat osteoblast-like cells: A single receptor stimulates intracellular accumulation of both cAMP and inositol trisphosphates and increases intracellular free calcium. Proc Natl Acad Sci USA 89: 2732-2736, 1992

20. Mannstadt M, Jüppner H and Gardella TJ: Receptors for PTH and PTHrP: Their biological importance and functional properties. Am J Physiol 277: F665-F675, 1999.

21. Kondo H, Guo J and Bringhurst FR: Cyclic adenosine monophosphate/protein kinase A mediates parathyroid hormone/parathyroid hormone-related protein receptor regulation of osteoclastogenesis and expression of RANKL and osteoprotegerin mRNAs by marrow stromal cells. J Bone Miner Res 17: 1667-1679, 2002.

22. Cheung R, Erclik MS and Mitchell J: Increased expression of G11alpha in osteoblastic cells enhances parathyroid hormone activation of phospholipase $\mathrm{C}$ and $\mathrm{AP}-1$ regulation of matrix metalloproteinase-13 mRNA. J Cell Physiol 204: 336-343, 2005.

23. Rey A, Manen D, Rizzoli R, Ferrari SL and Caverzasio J Evidences for a role of p38 MAP kinase in the stimulation of alkaline phosphatase and matrix mineralization induced by parathyroid hormone in osteoblastic cells. Bone 41: 59-67, 2007.

24. Ferrari SL, Behar V, Chorev M, Rosenblatt M and Bisello A Endocytosis of ligand-human parathyroid hormone receptor 1 complexes is protein kinase C-dependent and involves beta-arrestin 2 . Real-time monitoring by fluorescence microscopy. J Biol Chem 274: 29968-29975, 1999.

25. Vilardaga JP, Krasel C, Chauvin S, Bambino T, Lohse MJ and Nissenson RA: Internalization determinants of the parathyroid hormone receptor differentially regulate beta-arrestin/receptor association. J Biol Chem 277: 8121-8129, 2002.

26. De Camilli P, Emr SD, McPherson PS and Novick P. Phosphoinositides as regulators in membrane traffic. Science 271: 1533-1539, 1996.

27. Vahle JL, Sato M, Long GG, Young JK, Francis PC, Engelhardt JA, Westmore MS, Linda Y and Nold JB: Skeletal changes in rats given daily subcutaneous injections of recombinant human parathyroid hormone (1-34) for 2 years and relevance to human safety. Toxicol Pathol 30: 312-321, 2002.

28. Tashjian AH Jr and Gagel RF: Teriparatide [human PTH(1-34)] 2.5 years of experience on the use and safety of the drug for the treatment of osteoporosis. J Bone Miner Res 21: 354-365, 2006.

29. Watanabe A, Yoneyama S, Nakajima M, Sato N Takao-Kawabata R, Isogai Y, Sakurai-Tanikawa A, Higuchi K, Shimoi A, Yamatoya H, et al: Osteosarcoma in Sprague-Dawley rats after long-term treatment with teriparatide (human parathyroid hormone (1-34)). J Toxicol Sci 37: 617-629, 2012.

30. Subbiah V, Madsen VS, Raymond AK, Benjamin RS and Ludwig JA: Of mice and men: Divergent risks of teriparatide-induced osteosarcoma. Osteoporos Int 21: 1041-1045, 2010.

31. Harper KD, Krege JH, Marcus R and Mitlak BH: Comments on Initial experience with teriparatide in the United States. Curr Med Res Opin 22: 1927, 2006.

32. Harper KD, Krege JH, Marcus R and Mitlak BH: Osteosarcoma and teriparatide? J Bone Miner Res 22: 334, 2007.
33. Andrews EB, Gilsenan AW, Midkiff K, Sherrill B, Wu Y, Mann BH and Masica D: The US postmarketing surveillance study of adult osteosarcoma and teriparatide: Study design and findings from the first 7 years. J Bone Miner Res 27: 2429-2437, 2012.

34. Ho PW, Goradia A, Russell MR, Chalk AM, Milley KM, Baker EK, Danks JA, Slavin JL, Walia M, Crimeen-Irwin B, et al: Knockdown of PTHR1 in osteosarcoma cells decreases invasion and growth and increases tumor differentiation in vivo. Oncogene 34: 2922-2933, 2015

35. Yang D, Singh R, Divieti P, Guo J, Bouxsein ML and Bringhurst FR: Contributions of parathyroid hormone (PTH)/PTH-related peptide receptor signaling pathways to the anabolic effect of PTH on bone. Bone 40: 1453-1461, 2007.

36. Ardura JA, Wang B, Watkins SC, Vilardaga JP and Friedman PA Dynamic $\mathrm{Na}+\mathrm{H}+$ exchanger regulatory factor-1 association and dissociation regulate parathyroid hormone receptor trafficking at membrane microdomains. J Biol Chem 286: 35020-35029, 2011.

37. Kawane T, Mimura J, Yanagawa T, Fujii-Kuriyama Y and Horiuchi N: Parathyroid hormone (PTH) down-regulates $\mathrm{PTH} / \mathrm{PTH}-$ related protein receptor gene expression in UMR-106 osteoblast-like cells via a $3^{\prime}, 5^{\prime}$-cyclic adenosine monophosphate-dependent, protein kinase A-independent pathway. J Endocrinol 178: 247-256, 2003

38. Evans DB, Hipskind RA and Bilbe G: Analysis of signaling pathways used by parathyroid hormone to activate the c-fos gene in human SaOS2 osteoblast-like cells. J Bone Miner Res 11: 1066-1074, 1996

39. Pearman AT, Chou WY, Bergman KD, Pulumati MR and Partridge NC: Parathyroid hormone induces c-fos promoter activity in osteoblastic cells through phosphorylated cAMP response element (CRE)-binding protein binding to the major CRE. J Biol Chem 271: 25715-25721, 1996.

40. Liao J and McCauley LK: Skeletal metastasis: Established and emerging roles of parathyroid hormone related protein (PTHrP). Cancer Metastasis Rev 25: 559-571, 2006.

41. Pasquini GM, Davey RA, Ho PW, Michelangeli VP, Grill V, Kaczmarczyk SJ and Zajac JD: Local secretion of parathyroid hormone-related protein by an osteoblastic osteosarcoma (UMR 106-01) cell line results in growth inhibition. Bone 31: 598-605, 2002.

42. García-Martín A, Acitores A, Maycas M, Villanueva-Peñacarrillo ML and Esbrit P: Src kinases mediate VEGFR2 transactivation by the osteostatin domain of PTHrP to modulate osteoblastic function. J Cell Biochem 114: 1404-1413, 2013.

43. Jemtland R, Rian E, Olstad OK, Haug E, Bruland OS, Bucht E and Gautvik KM: Two human osteoblast-like osteosarcoma cell lines show distinct expression and differential regulation of parathyroid hormone-related protein. J Bone Miner Res 14: 904-914, 1999.

44. Gagiannis S, Müller M, Uhlemann S, Koch A, Melino G, Krammer PH, Nawroth PP, Brune M and Schilling T: Parathyroid hormone-related protein confers chemoresistance by blocking apoptosis signaling via death receptors and mitochondria. Int $\mathbf{J}$ Cancer 125: 1551-1557, 2009.

45. Kresse H and Schönherr E: Proteoglycans of the extracellular matrix and growth control. J Cell Physiol 189: 266-274, 2001

46. Afratis N, Gialeli C, Nikitovic D, Tsegenidis T, Karousou E, Theocharis AD, Pavão MS, Tzanakakis GN and Karamanos NK: Glycosaminoglycans: Key players in cancer cell biology and treatment. FEBS J 279: 1177-1197, 2012.

47. Sanderson RD, Yang Y, Suva LJ and Kelly T: Heparan sulfate proteoglycans and heparanase - partners in osteolytic tumor growth and metastasis. Matrix Biol 23: 341-352, 2004

48. Maxwell CA, McCarthy J and Turley E: Cell-surface and mitotic-spindle RHAMM: Moonlighting or dual oncogenic functions? J Cell Sci 121: 925-932, 2008.

49. Xu R, Boudreau A and Bissell MJ: Tissue architecture and function: Dynamic reciprocity via extra- and intra-cellular matrices. Cancer Metastasis Rev 28: 167-176, 2009.

50. Kouvidi K, Nikitovic D, Berdiaki A and Tzanakakis GN: Hyaluronan/RHAMM interactions in mesenchymal tumor pathogenesis: Role of growth factors. Adv Cancer Res 123: 319-349, 2014.

51. Nikitovic D, Chalkiadaki G, Berdiaki A, Aggelidakis J, Katonis P, Karamanos NK and Tzanakakis GN: Lumican regulates osteosarcoma cell adhesion by modulating TGF $\beta 2$ activity. Int J Biochem Cell Biol 43: 928-935, 2011.

52. Unni KK: Osteosarcoma of bone. J Orthop Sci 3: 287-294, 1998 
53. Benayahu D, Shur I, Marom R, Meller I and Issakov J: Cellular and molecular properties associated with osteosarcoma cells. J Cell Biochem 84: 108-114, 2001.

54. Nikitovic D, Tsatsakis AM, Karamanos NK and Tzanakakis GN: The effects of genistein on the synthesis and distribution of glycosaminoglycans/proteoglycans by two osteosarcoma cell lines depends on tyrosine kinase and the estrogen receptor density. Anticancer Res 23 (1A): 459-464, 2003.

55. Nikitovic D, Zafiropoulos A, Katonis P, Tsatsakis A, Theocharis AD, Karamanos NK and Tzanakakis GN: Transforming growth factor-beta as a key molecule triggering the expression of versican isoforms $\mathrm{v} 0$ and $\mathrm{v} 1$, hyaluronan synthase- 2 and synthesis of hyaluronan in malignant osteosarcoma cells. IUBMB Life 58: 47-53, 2006.

56. Nikitovic D, Berdiaki K, Chalkiadaki G, Karamanos N and Tzanakakis G: The role of SLRP-proteoglycans in osteosarcoma pathogenesis. Connect Tissue Res 49: 235-238, 2008.

57. Nikitovic D, Aggelidakis J, Young MF, Iozzo RV, Karamanos NK and Tzanakakis GN: The biology of small leucine-rich proteoglycans in bone pathophysiology. J Biol Chem 287: 33926-33933, 2012.

58. Datta NS and Abou-Samra AB: PTH and PTHrP signaling in osteoblasts. Cell Signal 21: 1245-1254, 2009.

59. Sabbieti MG, Agas D, Xiao L, Marchetti L, Coffin JD, Doetschman T and Hurley MM: Endogenous FGF-2 is critically important in PTH anabolic effects on bone. J Cell Physiol 219: 143-151, 2009.

60. Teplyuk NM, Haupt LM, Ling L, Dombrowski C, Mun FK, Nathan SS, Lian JB, Stein JL, Stein GS, Cool SM, et al: The osteogenic transcription factor Runx 2 regulates components of the fibroblast growth factor/proteoglycan signaling axis in osteoblasts. J Cell Biochem 107: 144-154, 2009.

61. Datsis GA, Berdiaki A, Nikitovic D, Mytilineou M, Katonis P, Karamanos NK and Tzanakakis GN: Parathyroid hormone affects the fibroblast growth factor-proteoglycan signaling axis to regulate osteosarcoma cell migration. FEBS J 278: 3782-3792, 2011.

62. Zafiropoulos A, Nikitovic D, Katonis P, Tsatsakis A, Karamanos NK and Tzanakakis GN: Decorin-induced growth inhibition is overcome through protracted expression and activation of epidermal growth factor receptors in osteosarcoma cells. Mol Cancer Res 6: 785-794, 2008.

63. Nikitovic D, Zafiropoulos A, Tzanakakis GN, Karamanos NK and Tsatsakis AM: Effects of glycosaminoglycans on cell proliferation of normal osteoblasts and human osteosarcoma cells depend on their type and fine chemical compositions. Anticancer Res 25: 2851-2856, 2005.

64. El Khassawna T, Böcker W, Brodsky K, Weisweiler D, Govindarajan P, Kampschulte M, Thormann U, Henss A, Rohnke M, Bauer N, et al: Impaired extracellular matrix structure resulting from malnutrition in ovariectomized mature rats. Histochem Cell Biol 144: 491-507, 2015.

65. Wang X, Harimoto K, Xie S, Cheng H, Liu J and Wang Z: Matrix protein biglycan induces osteoblast differentiation through extracellular signal-regulated kinase and Smad pathways. Biol Pharm Bull 33: 1891-1897, 2010.

66. Ruan K, Bao S and Ouyang G: The multifaceted role of periostin in tumorigenesis. Cell Mol Life Sci 66: 2219-2230, 2009.

67. Fortunati D, Reppe S, Fjeldheim AK, Nielsen M, Gautvik VT and Gautvik KM: Periostin is a collagen associated bone matrix protein regulated by parathyroid hormone. Matrix Biol 29: 594-601, 2010.

68. Nikitovic D, Kouvidi K, Kavasi RM, Berdiaki A and Tzanakakis GN: Hyaluronan/Hyaladherins - a Promising Axis for Targeted Drug Delivery in Cancer. Curr Drug Deliv 13: 500-511, 2016.
69. Midura RJ, Evanko SP and Hascall VC: Parathyroid hormone stimulates hyaluronan synthesis in an osteoblast-like cell line. J Biol Chem 269: 13200-13206, 1994.

70. Midura RJ, Su X, Morcuende JA, Tammi M and Tammi R: Parathyroid hormone rapidly stimulates hyaluronan synthesis by periosteal osteoblasts in the tibial diaphysis of the growing rat. J Biol Chem 278: 51462-51468, 2003.

71. Berdiaki A, Datsis GA, Nikitovic D, Tsatsakis A, Katonis P, Karamanos NK and Tzanakakis GN: Parathyroid hormone (PTH) peptides through the regulation of hyaluronan metabolism affect osteosarcoma cell migration. IUBMB Life 62: 377-386, 2010.

72. Pacheco-Costa R, Campos JF, Katchburian E, de Medeiros VP, Nader HB, Nonaka KO, Plotkin LI and Reginato RD: Modifications in bone matrix of estrogen-deficient rats treated with intermittent PTH. BioMed Res Int 2015: 454162, 2015.

73. Kido A, Tsutsumi M, Iki K, Takahama M, Tsujiuchi T, Morishita T, Tamai S and Konishi Y: Overexpression of matrix metalloproteinase (MMP)-9 correlates with metastatic potency of spontaneous and 4-hydroxyaminoquinoline 1-oxide (4-HAQO)-induced transplantable osteosarcomas in rats. Cancer Lett 137: 209-216, 1999 .

74. Wang J, Shi Q, Yuan TX, Song QL, Zhang Y, Wei Q, Zhou L, Luo J, Zuo G, Tang M, et al: Matrix metalloproteinase 9 (MMP-9) in osteosarcoma: Review and meta-analysis. Clin Chim Acta 433: 225-231, 2014.

75. Deryugina EI and Quigley JP: Matrix metalloproteinases and tumor metastasis. Cancer Metastasis Rev 25: 9-34, 2006.

76. Husmann K, Arlt MJ, Muff R, Langsam B, Bertz J, Born W and Fuchs B: Matrix Metalloproteinase 1 promotes tumor formation and lung metastasis in an intratibial injection osteosarcoma mouse model. Biochim Biophys Acta 1832: 347-354, 2013.

77. Egeblad M and Werb Z: New functions for the matrix metalloproteinases in cancer progression. Nat Rev Cancer 2: 161-174, 2002.

78. Shuman Moss LA, Jensen-Taubman S and Stetler-Stevenson WG: Matrix metalloproteinases: Changing roles in tumor progression and metastasis. Am J Pathol 181: 1895-1899, 2012.

79. Uchibori M, Nishida Y, Nagasaka T, Yamada Y, Nakanishi K and Ishiguro $\mathrm{N}$ : Increased expression of membrane-type matrix metalloproteinase-1 is correlated with poor prognosis in patients with osteosarcoma. Int J Oncol 28: 33-42, 2006.

80. Himelstein BP, Asada N, Carlton MR and Collins MH: Matrix metalloproteinase-9 (MMP-9) expression in childhood osseous osteosarcoma. Med Pediatr Oncol 31: 471-474, 1998.

81. Kimura R, Ishikawa C, Rokkaku T, Janknecht R and Mori N: Phosphorylated c-Jun and Fra-1 induce matrix metalloproteinase-1 and thereby regulate invasion activity of 143B osteosarcoma cells. Biochim Biophys Acta 1813: 1543-1553, 2011.

82. Lee M and Partridge NC: Parathyroid hormone activation of matrix metalloproteinase-13 transcription requires the histone acetyltransferase activity of p300 and PCAF and p300-dependent acetylation of PCAF. J Biol Chem 285: 38014-38022, 2010.

83. Zhu W, Yang ML, Yang GY, Boden G and Li L: Changes in serum runt-related transcription factor 2 levels after a 6-month treatment with recombinant human parathyroid hormone in patients with osteoporosis. J Endocrinol Invest 35: 602-606, 2012. 